ation and other aspects of photomorphogenesis. Neither book conveys the importance of phytochrome in an ecological context, even though so much has been learned about this in recent years.

Devlin and Witham may just have the edge as far as the student is concerned, for in their book the diagrams and photographs are rather better integrated with the text; nonetheless, Plant Physiology sometimes falls behind in the depth and "up-todateness" of its coverage. But while any attempt to deal with such a broad area is bound to be open to criticism, I would be happy to recommend either of these books. Students of biological science who are likely to meet plant physiology at any time in their university career can be directed to both works with confidence.

Nobel's book, which follows his earlier Biophysical Plant Physiology, published by Freeman in 1974, is not comparable with the preceding two works, for it deals only with those parts of plant function which are amenable to physicochemical analysis ion and water movement, energy transduction and bioenergetics, temperatureenergy budgets, gaseous fluxes in leaves, and aspects of photoperception. In the author's words, the book is "an attempt to integrate at an introductory level, certain relevant parts of the physical sciences with plant biology". It succeeds in this aim. Treatment is at a depth not found in any other plant physiology textbook of which I am aware, yet Nobel assumes no more than a first-year university background in physics, chemistry and mathematics on the part of his readers. All interested in ecophysiology, transport phenomena and bioenergetics will find this an invaluable if not essential companion to books dealing with these subjects in a more conventional manner, and plant physiologists in general will appreciate the appendices on the symbols, abbreviations, physical constants, co-efficients and conversion factors with which we are having to become familiar.

Bleasdale's Plant Physiology in Relation to Horticulture is intended for a different readership, primarily for horticulturists. It gives an elementary account of those aspects of plant function about which such practitioners should be aware, but it would make useful reading for biologists who wish to know something about the practical importance of plant physiology. The book is a revised version of the first edition (1973) and the author admits to surprise at how little needed to be changed. But I wish that he hadn't been so conservative, at least with the references. For example, the average age of the citations on photosynthesis (in the chapter on seedling physiology) is 37 years, and even the "new" chapter on the seed mostly refers to material nearly 20 years old.

Michael Black is Senior Lecturer in Plant Physiology at Queen Elizabeth College, University of London.

\section{Past attractions}

\section{Keith Allen}

Paleobotany and the Evolution of Plants.

By Wilson N. Stewart.

Cambridge University Press: 1983.

Pp.405. £17.50, \$29.95.

Introduction to Palaeobiology: General Palaeontology.

By B. Ziegler.

Ellis Horwood/Halsted: 1983. Pp.225.

Hbk £30, \$69.95; pbk £12.50, \$29.95.

Ancient Sedimentary Environments and the Habitats of Living Organisms:

Introduction to Palaeoecology.

By Jean-Claude Gall.

Springer-Verlag: 1983. Pp.219. DM 60, $\$ 24.80$.

A TEXTBOOK can be compared with a member of the opposite sex. If the initial layout is attractive, then you may wish to continue the acquaintance. Paleobotany and the Evolution of Plants by W.N. Stewart is a good-looking book and repays closer attention. The text is well laid out, the photographs well produced, and the new and redrawn figures are of high quality (no acknowledgement is given for these, so I assume they were drawn by Stewart himself).

After a gap of almost twenty years (1961-1981) when no general British or North American palaeobotany textbook was published, Wilson's book follows closely on the heels of Thomas Taylor's Paleobotany: An Introduction to Fossil Plant Biology (for review see Nature 295, $468 ; 1982)$. Both texts are aimed at a similar audience, primarily the palaeobotanist and botanist, with little for the geologist. Stewart's chapters follow the usual sequence - starting with types of plant preservation and techniques for their study, continuing with classification, and then running through the taxa from cyanobacteria to angiosperms.

This textbook is well written and well researched. In all, it is a pleasure to own. My main criticism is that the angiosperms, which have after all dominated the Earth's flora since Upper Cretaceous times, are given only 27 pages in a book of 400 . This is a pity; at present there is a lot of interesting research being carried out on early angiosperms which might have been mentioned.

Although the task of giving an overview of palaeobiology in 225 pages seems a daunting one, my initial impression of

\section{Textbook supplement - prices}

Where possible both dollar prices pertaining in the United States and sterling prices for the United Kingdom are given in the bibliographical details for each book. Export prices will generally be higher. If a dollar or sterling price is not cited, the book is not available in one of the two countries. However readers should check both price and availability of books before ordering.
Ziegler's Introduction to Palaeobiology was favourable. It is well laid out, and is accompanied by pleasing illustrations. Here I thought is a book to interest biologists and geologists alike. Sadly, on delving deeper, my initial enthusiasm turned to disappointment.

The book was originally published in German in 1972; it is in part out of date and has not been thoroughly researched. In Chapter 1, for instance, "Major Subdivisions of the Organic World", errors are woefully abundant. We are told that living things can be divided into two kingdoms, then four are listed. Phyla are used in the Plant Kingdom when, under the Rules of the Botanical Code, Divisions are mandatory. The Mastigophora are included in both the Plant and Animal Kingdoms; what is wrong with the Kingdom Protista for the unicellular algae and protozoa? The name Phycomycetes, used here, became "extinct" in the early 1960 s, while according to Ziegler Rhynia, Lepidodendron and Equisetum are ferns and gymnosperms are flowering plants. There are many other inaccuracies in this chapter and it is all very confusing for students.

Topics covered in other chapters include evolution, mode of life, ecology and biogeography. In some there are further serious errors and the reference lists for each chapter are too short and inadequate. There are other, better books on the subject, for example D. M. Raup and S. M. Stanley's Principles of Paleontology (W. H. Freeman, 2nd Edn 1978), which students would be advised to turn to first.

Gall's Ancient Sedimentary Environments and the Habitats of Living Organisms looks less attractive. Unkindly you might say that in appearance it is a book of prominent headings interspersed with text. Nevertheless the more I read this book, the more I liked it. It is in two parts, the first giving information deduced from the fossils and sediments (e.g. modes of life, sediments and sedimentary environments and fossiliferous horizons), the second dealing with nine ancient sedimentary environments of differing types, from the Precambrian Ediacaran fauna to an Aecheulian hunter's cave. It includes discussion of various marine, lagoonal, deltaic and fluviatile environments.

It seems to me, however, that this book is too short; a further 50 pages would have allowed greater depth and the elucidation of somewhat telegraphic statements. It was written in 1975, and does not appear to have been updated for translation - only four references are given from the past decade - while a palaeobotanist could have advised Gall on several errors. But this is a generally good elementary text, which could be of use at first-year university level, particularly for biologists needing some relevant geology.

Keith Allen is Senior Lecturer in Botany at the University of Bristol. 